\title{
BMJ Open Body mass index and clinical outcomes in patients after ischaemic stroke in South Korea: a retrospective cohort study
}

\author{
HeeKyoung Choi, ${ }^{1,2}$ Hyo Suk Nam, ${ }^{3}$ Euna Han ${ }^{\odot 1,4}$
}

To cite: Choi H, Nam HS, Han E. Body mass index and clinical outcomes in patients after ischaemic stroke in South Korea: a retrospective cohort study. BMJ Open 2019;9:e028880. doi:10.1136/ bmjopen-2018-028880

- Prepublication history for this paper is available online. To view these files, please visit the journal online (http://dx.doi. org/10.1136/bmjopen-2018028880).

HSN and EH contributed equally.

Received 31 December 2018 Revised 26 July 2019 Accepted 29 July 2019
Check for updates

(c) Author(s) (or their employer(s)) 2019. Re-use permitted under CC BY-NC. No commercial re-use. See rights and permissions. Published by BMJ.

For numbered affiliations see end of article.

Correspondence to Dr Euna Han; eunahan@yonsei.ac.kr

Dr Hyo Suk Nam; hsnam@yuhs.ac

\section{ABSTRACT}

Objectives Although obesity is a risk factor for stroke, its impact on mortality in patients with stroke remains unclear. In this study, we aimed to evaluate the relationship between body mass index (BMI) and mortality due to ischaemic stroke among adults aged 20 years and above in Korea.

Design Retrospective cohort study.

Setting A tertiary-hospital-based stroke registry linked to the death records.

Participants 3599 patients admitted for ischaemic stroke from January 2007 to June 2013.

Outcome measures The HRs for all-cause and strokerelated mortality were calculated using Cox proportional hazards models. Progression from stroke-related mortality was assessed using the Fine-Grey competing risk model, treating other-cause mortality as a competing risk. Adjustments were made for age, gender, smoking status, Charlson comorbidity index, cardiovascular or non-cardiovascular comorbidities, stroke severity, severity related to other medical conditions, complications and enrolment year. We repeated the analysis with stratification based on age groups (less than 65 vs 65 years and above). Results For stroke-related mortality, there was no significant difference among the four BMl groups. The risk of all-cause mortality was $36 \%$ higher in the underweight group than in the normal weight group (long-term $\mathrm{HR}=1.36,95 \% \mathrm{Cl}: 1.04$ to 1.79 ), whereas the mortality risk of the obese group was significantly lower $(\mathrm{HR}=0.66$, $95 \% \mathrm{Cl}: 0.54$ to 0.81$)$. Although this relationship was not estimated in the younger group, it was found that obesity had a protective effect on the all-cause mortality in the elderly (long-term $\mathrm{HR}=0.66,95 \% \mathrm{Cl}$ : 0.52 to 0.83 ).

Conclusions Obesity is more likely to reduce mortality risk than normal weight, especially in elderly patients.

\section{INTRODUCTION}

Obesity is one of the established risk factors for stroke, in which prevention guidelines recommend weight reduction. ${ }^{1}$ However, in patients who have experienced a stroke, an inverse relationship was reported between obesity and unfavourable clinical outcomes, such as readmission, stroke recurrence and mortality, in contrast to that of the general population. ${ }^{2-8}$ This paradox was also observed

\section{Strengths and limitations of this study}

- The relationship between body mass index and mortality was evaluated by controlling the variables related to various diseases, which could not be obtained in previous studies.

- We addressed the existence of multi-morbidity by Charlson comorbidity index.

- This is a hospital-based study involving a single tertiary hospital whose data could not be generalised.

in other chronic diseases such as heart failure, diabetes, chronic kidney disease, and peripheral vascular disease. ${ }^{9-12}$

The obesity paradox remains to be fully explained and even criticised as an artificial finding associated with selection bias, that is, a confounding result due to uncontrolled risk factors commonly correlated with mortality and obesity. ${ }^{13-15}$ One obvious confounder is comorbidities. Some comorbidities such as infections or malignant diseases can cause unintended weight loss and death. ${ }^{16}$ Other significant confounders are age and stroke severity. In several studies on the obesity paradox, patients with lower body mass index (BMI) were older and had higher stroke severity, consequently causing an increased mortality risk. ${ }^{17-19}$ Previous studies on Korean patients with ischaemic stroke ${ }^{1819}$ also showed that the initial relationship between obesity and short-term clinical outcome ${ }^{19}$ or longterm mortality ${ }^{18}$ cease to exist after adjusting for stroke severity.

Comorbidities, age and stroke severity are the most critical outcome determinants after an ischaemic stroke incident. Hence, in this paper, we examine the relationship between obesity-related mortality and all-cause mortality among patients with ischaemic stroke after adjusting the effect of stroke severity (based on the National Institutes of Health Stroke Scale (NIHSS) 
score) and other severe comorbidities from a detailed registry data in a clinical setting. The NIHSS score is an excellent indicator of stroke severity. We also determine whether the relationship is consistent regardless of patients' age.

\section{MATERIALS AND METHODS \\ Data source and study subjects}

The study subjects were from the Yonsei Stroke Registry, a hospital-based stroke registry established in $1994 .^{20}$ We identified all patients aged 20 years and above who were admitted for acute ischaemic stroke from January 2007 to June 2013. The Yonsei Stroke Registry admits only patients with acute ischaemic stroke who were seen by a neurologist within 7 days of clinical onset. All of the patients have acute cerebral infarctions and have been presented to the neurologists within 7 days of onset. The diagnosis of cerebral infarction was based on clinical features related to neuroimaging studies such as CT or MRI, which was confirmed by the agreement of two or more staff neurologists. We excluded patients younger than 20 years and those without height or weight data. Registered patients were routinely followed up in the outpatient clinic until their death. Moreover, the deaths were confirmed by matching the death records and the cause of death obtained from the Korean National Statistical Office. The causes of death were classified according to the International Classification of Disease, 10th revision. Furthermore, stroke-related mortality included the fatal stroke (I60-64), ${ }^{21}$ whereas cardiovascular-event-related mortality included I00-I99.

\section{Variables}

Obesity

Height and weight were measured at the time of registration. BMI was calculated as the ratio of weight $(\mathrm{kg})$ and the square of height $\left(\mathrm{m}^{2}\right)$. Then, the patients were classified into four groups based on their BMI at the time of stroke. Obese I and obese II categories were combined to a single obese category, and BMI levels were classified according to the guidelines for the Asian-Pacific population $^{22}$ : underweight $\left(\mathrm{BMI}<18.5 \mathrm{~kg} / \mathrm{m}^{2}\right)$, normal weight $\left(18.5 \leq \mathrm{BMI}<23 \mathrm{~kg} / \mathrm{m}^{2}\right)$, overweight $\left(23 \leq \mathrm{BMI}<25 \mathrm{~kg} / \mathrm{m}^{2}\right)$ and obese $\left(\mathrm{BMI} \geq 25 \mathrm{~kg} / \mathrm{m}^{2}\right.$ ). The normal weight group was used as the reference group.

\section{Clinical outcomes}

The primary outcomes were all-cause mortality in the short term (within 3 months), intermediate term (within 1 year) and long term (longer than 1 year) after the stroke incident. Meanwhile, the secondary outcomes were stroke-related mortality and cardiovascular-event-related mortality, and the occurrence of those outcomes was ascertained based on the discharge records or death records.

\section{Covariates}

The initial stroke severity was evaluated using the NIHSS score, which ranges from 0 to 42 based on the 15 elements of neurological examinations in various aspects of individual physical functions. ${ }^{23}$ To identify potential confounders of the relationship between BMI and mortality, we reviewed the literature and obtained the following covariates from the registry: age, ${ }^{24}$ gender, ${ }^{25}{ }^{26}$ current smoking status, ${ }^{1}{ }^{27} 28$ any complication that occurred during admission ${ }^{29}$ and comorbiditiesincluding previous stroke, ${ }^{29}$ diabetes, ${ }^{29}{ }^{30}$ hypercholesterolaemia, ${ }^{31}$ depression, ${ }^{32}$ dementia, ${ }^{33}$ anaemia, ${ }^{34}$ atrial fibrillation ${ }^{35}$ and active cancer. In addition to the NIHSS score, we included the Charlson comorbidity index (CCI) and cardiovascular risk parameters at admission, such as blood glucose level, systolic blood pressure and total cholesterol level at the time of the index stroke diagnosis.

Active cancer was defined as any cancer diagnosed within 6 months before the stroke: recently recurrent cancer, progressive cancer, or any malignancy requiring curative or palliative treatment within the previous 6 months. ${ }^{36}$ Complications included brain herniation, intracerebral haemorrhage, any infection (such as pneumonia, urinary tract infection and sepsis) and any bleeding other than intracerebral haemorrhage. The CCI is a widely used weighted composite index for comorbidities, such as myocardial infarction, congestive heart failure, peripheral vascular disease or bypass, previous cerebrovascular accident or transient ischaemic attack, dementia, chronic pulmonary disease, gastrointestinal ulcer disease, liver disease, moderate or severe renal disease, connective tissue disease or rheumatic disease, diabetes, diabetes with end-organ damage, AIDS, non-metastatic solid tumour, leukaemia, lymphoma, multiple myeloma, and metastatic tumour. ${ }^{37}$ Note that we did not include the age factor when calculating CCI.

Patients with hypertension were managed to maintain normal blood pressure. Shock is also a critical life-threatening emergency in patients with stroke. Therefore, we considered both hypertension and hypotension as risk factors for mortality. Since blood pressure fluctuates and only one measurement was obtained under a stressful condition, we defined the lower risk range of systolic blood pressure as 90 to $180 \mathrm{~mm} \mathrm{Hg} .{ }^{38}$ It is known that both hypoglycaemia and hyperglycaemia can increase the risk of death. Since diabetes was included in the covariate and considering recommendations on glycaemic control and meta-analysis result, ${ }^{30}{ }^{39-41}$ we defined the reference level of blood glucose as $3.9-10 \mathrm{mmol} / \mathrm{L}(70-180 \mathrm{mg}$ / $\mathrm{dL}$ ). Considering that stroke treatment may last over 7 years, all models were adjusted based on the enrolment year. Using 2007 as the reference group, we created dummy variables representing the year of initial stroke hospitalisation.

Subgroup analyses were conducted based on age (less than 65 and 65 years and above) for all-cause mortality. 


\section{Statistical analysis}

The characteristics of the study groups were analysed using analysis of variance tests, and Kruskal-Wallis test and $\chi^{2}$ tests were used for continuous variables and categorical variables, respectively. Kaplan-Meier analysis was used to determine the relationship between categorical BMI and all-cause or stroke-related mortality. We used multivariate Cox proportional hazard models to analyse the relationship between BMI and mortality within 3 months, 1 year and over 1 year. The multivariate models were adjusted for age, gender and smoking status. The same analysis was conducted by additionally adjusting for comorbidities, CCI, shock or extremely high blood pressure, hypoglycaemia or hyperglycaemia at admission, total cholesterol level at admission, NIHSS score, any complications, enrolment year, treatment modalities (any thrombolysis, tissue plasminogen activator use, intra-arterial thrombolysis, mechanical thrombectomy and stent insertion), and statin use. Progression from stroke-related mortality was assessed using the Fine-Grey competing risk model, treating other-cause mortality as a competing risk. We also performed competing risk analysis with cardiovascular-event-related death as the primary event of interest and non-cardiovascular mortality as a competing event. Stratified analyses based on the patient's age group were performed. However, because dementia and hypoglycaemia were rare in younger patients, we excluded these variables for ages less than 65 years in the subgroup analysis. Furthermore, statistical analyses were performed using Stata V.14 (College Town, TX, USA).

\section{Patient and public involvement}

Patients and the public were not involved in this analysis.

\section{RESULTS}

\section{Sample characteristics}

A total of 3599 patients with ischaemic stroke aged 20 years and older were identified from the registry from January 2007 to June 2013. In all, 15 patients $(0.4 \%)$ were excluded because of missing height or weight data, and thus, only 3584 patients remained as the final sample. Compared with patients with accurate height and weight information, those without such data were older, had a severe stroke and showed higher short-term mortality.

Table 1 summarises the baseline characteristics of the final sample. The mean age of the studied patients was 66 (range, 20-104) years. The mean BMI was $23.7 \mathrm{~kg} / \mathrm{m}^{2} ; 164(4.6 \%)$ patients were underweight, $1321(36.9 \%)$ were normal weight, $943(26.3 \%)$ were overweight and 1156 (32.2\%) were obese. Patients were followed up for a mean period of 1133 days after the index event. A total of 824 patients $(23 \%)$ died, and the mean duration until death was 545 days, where 284 patients $(7.9 \%)$ died of a stroke, with a mean duration until stroke-related death of 360 days. In the subgroup of patients aged less than 65 years, $159(11.1 \%)$ died
Table 1 Summary statistics

\begin{tabular}{|c|c|}
\hline Variables $(n=3584)$ & $\begin{array}{l}\text { Mean } \pm \text { SD, N (\%), } \\
\text { median (IQR) }\end{array}$ \\
\hline \multicolumn{2}{|l|}{ Key independent variables } \\
\hline BMI $\left(k g / m^{2}\right)$ & $23.7 \pm 3.3(11.4-40.1)$ \\
\hline Underweight (BMI <18.5) & $164(4.6)$ \\
\hline 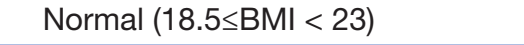 & $1321(36.9)$ \\
\hline Overweight $(23 \leq \mathrm{BMI}<25)$ & $943(26.3)$ \\
\hline Obese (BMI $\geq 25)$ & $1156(32.2)$ \\
\hline \multicolumn{2}{|l|}{ Outcomes } \\
\hline \multicolumn{2}{|l|}{ All-cause mortality } \\
\hline Within 3 months & $248(6.9)$ \\
\hline Within 1 year & $425(11.9)$ \\
\hline After 1 year & $824(23.0)$ \\
\hline \multicolumn{2}{|l|}{ Stroke-related mortality } \\
\hline Within 3 months & $130(3.6)$ \\
\hline Within 1 year & $187(5.2)$ \\
\hline After 1 year & $284(7.9)$ \\
\hline \multicolumn{2}{|l|}{ Covariates } \\
\hline NIHSS on admission & $3(1-7)$ \\
\hline Age & $66 \pm 12.4$ \\
\hline 20-64 years & $1439(40.2)$ \\
\hline$\geq 65$ years & 2145 (59.8) \\
\hline \multicolumn{2}{|l|}{ Sex } \\
\hline Male* $^{*}$ & $2175(60.7)$ \\
\hline \multicolumn{2}{|l|}{ Comorbidities } \\
\hline Atrial fibrillation* & $803(22.4)$ \\
\hline Depression* & $197(5.5)$ \\
\hline Dementia* & $107(3.0)$ \\
\hline $\begin{array}{l}\text { Previous stroke or transient } \\
\text { ischaemic } \text { attack }^{*}\end{array}$ & $470(13.1)$ \\
\hline Anaemia* $^{*}$ & $616(17.2)$ \\
\hline Active cancer* & $205(5.7)$ \\
\hline Liver disease $^{*}$ & $109(3.0)$ \\
\hline Moderate or severe renal disease* & $300(8.4)$ \\
\hline Diabetes* $^{*}$ & $1138(31.8)$ \\
\hline Hypercholesterolaemia* & $747(20.8)$ \\
\hline Charlson comorbidity index & $1[0-2)$ \\
\hline Current smoking* & $854(23.8)$ \\
\hline
\end{tabular}

Initial systolic blood pressure ( $\mathrm{mm}$

$\mathrm{Hg})$

\begin{tabular}{ll}
$90 \leq \mathrm{SBP}<180$ & $2913(81.3)$ \\
Shock $(\mathrm{SBP}<90)^{\star}$ & $12(0.3)$ \\
$\begin{array}{l}\text { Extremely high blood pressure } \\
(\mathrm{SBP} \geq 180)^{\star}\end{array}$ & $659(18.4)$ \\
\hline Initial blood glucose $(\mathrm{mmol} / \mathrm{L})$ & \\
$3.9 \leq$ glucose $<10$ & $2935(81.9)$ \\
\hline Hypoglycaemia (glucose $<3.9)^{\star}$ & $15(0.42)$ \\
\hline
\end{tabular}

Continued 
Table 1 Continued

\begin{tabular}{|c|c|}
\hline Variables $(n=3584)$ & $\begin{array}{l}\text { Mean } \pm S D, N(\%) \\
\text { median (IQR) }\end{array}$ \\
\hline 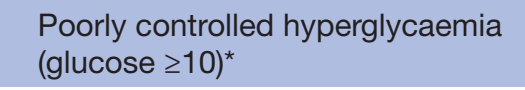 & $634(17.7)$ \\
\hline Initial total cholesterol (mg/dL) & $181 \pm 43$ \\
\hline \multicolumn{2}{|l|}{ Subtypes of ischaemic stroke } \\
\hline Large artery atherosclerosis & $741(20.7)$ \\
\hline Cardioembolism & $980(27.3)$ \\
\hline Small vessel occlusion & $319(8.9)$ \\
\hline $\begin{array}{l}\text { Stroke of other determined } \\
\text { aetiology }\end{array}$ & $86(2.4)$ \\
\hline $\begin{array}{l}\text { Stroke of undetermined aetiology } \\
\text { because of incomplete evaluation }\end{array}$ & $10(0.3)$ \\
\hline $\begin{array}{l}\text { Stroke of undetermined aetiology } \\
\text { because of negative evaluation }\end{array}$ & $781(21.8)$ \\
\hline $\begin{array}{l}\text { Stroke of undetermined aetiology } \\
\text { because of two or more causes }\end{array}$ & $667(18.6)$ \\
\hline Any complications* & $588(16.4)$ \\
\hline
\end{tabular}

Treatment*

\begin{tabular}{ll}
\hline Any thrombolysis & $407(11.4)$ \\
\hline Tissue plasminogen activator & $275(7.7)$ \\
\hline Intra-arterial thrombolysis & $163(4.6)$ \\
\hline Mechanical thrombectomy & $126(3.5)$ \\
Stent insertion & $111(3.1)$ \\
\hline Antiplatelet & $1146(32.0)$ \\
\hline Anticoagulation & $206(5.8)$ \\
\hline Statin & $610(17)$ \\
\hline Fiscal year of stroke onset & \\
\hline 2007 & $522(14.6)$ \\
2008 & $541(15.1)$ \\
2009 & $642(17.9)$ \\
2010 & $512(14.3)$ \\
\hline 2011 & $561(15.6)$ \\
\hline 2012 & $523(14.6)$ \\
2013 & $283(7.9)$ \\
\hline
\end{tabular}

${ }^{*}$ Dummy variables.

BMI, body mass index; NIHSS, National Institute of Health Stroke Scale; SBP, systolic blood pressure.

during the follow-up period, whereas the mortality of elderly patients aged 65 years and above was $31 \%(665$ patients).

Table 2 shows the baseline characteristics among obesity subgroups. Underweight patients were older and more likely to have higher NIHSS scores, atrial fibrillation, anaemia, active cancer, shock and complications. Obese patients were younger and more likely to have diabetes, hypercholesterolaemia and higher initial total cholesterol.
Stroke-related mortality and cardiovascular-event-related mortality in the total population

Stroke-related mortality was highest in the underweight patients and lowest in the obese patients (see figure 1A). After adjustment of age, gender and smoking status, the overweight had a lower probability of long-term mortality—subdistribution HR (SHR) $=0.73,95 \%$ CI: 0.54 to $0.99-$ (see table 3, Model 1). However, after further adjustment of comorbidities, the obesity paradox disappeared (see table 3, Model 2). For cardiovascular-event-related mortality, the overweight and obese groups had a lower probability of long-term mortality $(\mathrm{SHR}=0.72$, $95 \%$ CI: 0.55 to 0.95 for the overweight group; $\mathrm{SHR}=0.67$, 95\% CI: 0.51 to 0.89 for the obese group) in Model 1 . After further adjustment, the obese group still had a lower probability of long-term mortality $(\mathrm{SHR}=0.66,95 \% \mathrm{CI}$ : 0.49 to 0.90 ; see table 3 , Model 2).

\section{All-cause mortality in the total population}

In the unadjusted analysis, all-cause mortality increased with lower BMI (see figure 1B). The all-cause mortality risks in covariate-adjusted analysis remained higher in the underweight group than in the normal weight group for all investigated durations (HR=1.55, 95\% CI: 1.00 to 2.42 for 3-month mortality; HR=1.54, 95\% CI: 1.09 to 2.18 for 1-year mortality; HR=1.43, 95\% CI: 1.09 to 1.87 for long-term mortality). By contrast, after adjusting for the confounding variables, the obese group had a lower risk than the normal weight group by $19 \%$ for 3 -month mortality (HR $=0.81,95 \%$ CI: 0.56 to 1.16 ), $27 \%$ for 1 -year mortality (HR $=0.73,95 \%$ CI: 0.55 to 0.99 ) and $34 \%$ for mortality of 1 year and above (HR=0.66, $95 \%$ CI: 0.54 to 0.82; see table 4).

\section{All-cause mortality stratified by age group}

The all-cause mortality was lower in the higher BMI groups in both elderly (of age 65 years and above) and younger (of age less than 65 years) subgroups (see figure 2A and B) in the unadjusted analyses. The obesity paradox was still observed even after adjustment for age, gender and smoking status and was more evident in the younger group in all investigated durations (see table 4, Model 1). However, after further adjustment for comorbidities, such associations disappeared in the younger group. By contrast, in the older age group, the mortality risk was maintained: higher mortality risk in the underweight group (HR=1.50, 95\% CI: 1.03 to 2.19 for 1-year mortality; $\mathrm{HR}=1.42,95 \% \mathrm{CI}: 1.06$ to 1.92 for long-term mortality) and lower mortality risk in the obese group (long-term $\mathrm{HR}=0.65,95 \%$ CI: 0.52 to 0.83 ; see table 4 , Model 2).

\section{DISCUSSION}

This study showed that the obesity paradox is not evident in stroke-related mortality. By contrast, the obesity paradox was highly associated with the all-cause death even after accounting for potential confounding of pre-existing comorbidities. We also found that such association 
Table 2 Univariate analysis of covariates between obesity groups

\begin{tabular}{|c|c|c|c|c|c|}
\hline Covariates & $\begin{array}{l}\text { Underweight } \\
(\mathrm{n}=164)\end{array}$ & $\begin{array}{l}\text { Normal weight } \\
(n=1321)\end{array}$ & $\begin{array}{l}\text { Overweight } \\
(\mathrm{n}=943)\end{array}$ & $\begin{array}{l}\begin{array}{l}\text { Obese } \\
(n=1156)\end{array} \\
\end{array}$ & $P$ value \\
\hline NIHSS on admission & $5(2-14)$ & $4(2-8)$ & $3(1-7)$ & $3(1-6)$ & $<0.001$ \\
\hline Age & $71.7 \pm 14.3$ & $67.6 \pm 12.4$ & $66.0 \pm 11.6$ & $63.3 \pm 12.2$ & $<0.001$ \\
\hline Sex, male & $80(48.8)$ & $773(58.5)$ & $640(67.9)$ & $682(59)$ & $<0.001$ \\
\hline Atrial fibrillation & $55(33.5)$ & $316(23.9)$ & $211(22.4)$ & $221(19.1)$ & $<0.001$ \\
\hline Depression & $17(10.4)$ & $83(6.3)$ & $47(5.0)$ & $50(4.3)$ & 0.006 \\
\hline Dementia & $8(4.9)$ & $42(3.2)$ & $34(3.6)$ & $23(2.0)$ & 0.06 \\
\hline $\begin{array}{l}\text { Previous stroke or transient } \\
\text { ischaemic attack }\end{array}$ & $27(16.5)$ & $161(12.2)$ & $119(12.6)$ & $163(14.1)$ & 0.284 \\
\hline Anaemia & $63(38.4)$ & $283(21.4)$ & $128(13.6)$ & $142(12.3)$ & $<0.001$ \\
\hline Active cancer & $13(7.9)$ & $91(6.9)$ & $52(5.5)$ & $49(4.2)$ & 0.022 \\
\hline Liver disease & $5(3.1)$ & $30(2.3)$ & $29(3.1)$ & $45(3.9)$ & 0.138 \\
\hline Moderate or severe renal disease & $21(12.8)$ & $130(9.8)$ & $66(7.0)$ & $83(7.2)$ & 0.006 \\
\hline Diabetes & $37(22.6)$ & $389(29.5)$ & $290(30.8)$ & $422(36.5)$ & $<0.001$ \\
\hline Hypercholesterolaemia & $23(14.0)$ & $245(18.6)$ & $189(20.0)$ & $290(25.1)$ & $<0.001$ \\
\hline Charlson comorbidity index & $1[0-2.5)$ & $1[0-2)$ & $1[0-2)$ & $1[0-2)$ & 0.016 \\
\hline Current smoking & $27(16.5)$ & $309(23.4)$ & $244(25.9)$ & $274(23.7)$ & 0.065 \\
\hline Shock (SBP <90) & $3(1.8)$ & $6(0.5)$ & $2(0.2)$ & $1(0.1)$ & 0.003 \\
\hline $\begin{array}{l}\text { Extremely high blood pressure (SBP } \\
\geq 180 \text { ) }\end{array}$ & $33(20.1)$ & $234(17.8)$ & $168(17.8)$ & $224(19.4)$ & 0.640 \\
\hline Initial hypoglycaemia (glucose <3.9) & $0(0)$ & $7(0.5)$ & $5(0.5)$ & $3(0.3)$ & 0.559 \\
\hline $\begin{array}{l}\text { Poorly controlled hyperglycaemia } \\
\text { (glucose } \geq 10 \text { ) }\end{array}$ & $23(14.0)$ & $219(16.6)$ & $165(17.5)$ & 227 (19.6) & 0.129 \\
\hline Initial total cholesterol (mmol/L) & $171 \pm 40$ & $179 \pm 42$ & $180 \pm 42$ & $186 \pm 45$ & $<0.001$ \\
\hline Large artery atherosclerosis & $28(17.1)$ & $255(19.3)$ & $180(19.1)$ & $278(24.1)$ & 0.006 \\
\hline Cardioembolism & $58(35.4)$ & $372(28.2)$ & $264(28.0)$ & $286(24.7)$ & 0.019 \\
\hline Small vessel occlusion & $14(8.5)$ & $112(8.5)$ & $90(9.5)$ & $103(8.9)$ & 0.850 \\
\hline Stroke of other determined aetiology & $4(2.4)$ & $32(2.4)$ & $21(2.2)$ & $29(2.5)$ & 0.980 \\
\hline $\begin{array}{l}\text { Stroke of undetermined aetiology } \\
\text { because of incomplete evaluation }\end{array}$ & $1(0.6)$ & $2(0.2)$ & $3(0.3)$ & $4(0.4)$ & 0.647 \\
\hline $\begin{array}{l}\text { Stroke of undetermined aetiology } \\
\text { because of negative evaluation }\end{array}$ & $29(17.7)$ & $279(21.1)$ & $212(22.5)$ & $261(22.6)$ & 0.448 \\
\hline $\begin{array}{l}\text { Stroke of undetermined aetiology } \\
\text { because of two or more causes }\end{array}$ & $30(18.3)$ & $269(20.4)$ & $173(18.4)$ & $195(16.9)$ & 0.168 \\
\hline Any complications & $50(30.5)$ & $239(18.1)$ & $133(14.1)$ & $166(14.4)$ & $<0.001$ \\
\hline Any thrombolysis & $26(15.9)$ & $158(12.0)$ & $106(11.2)$ & $117(10.1)$ & 0.136 \\
\hline Tissue plasminogen activator & $19(11.6)$ & $107(8.1)$ & $62(6.6)$ & $87(7.5)$ & 0.137 \\
\hline Intra-arterial thrombolysis & $12(7.3)$ & $71(5.4)$ & $43(4.6)$ & $37(3.2)$ & 0.020 \\
\hline Mechanical thrombectomy & $4(2.4)$ & $49(3.7)$ & $41(4.4)$ & $32(2.8)$ & 0.209 \\
\hline Stent insertion & $5(3.1)$ & $40(3.0)$ & $42(4.5)$ & $24(2.1)$ & 0.020 \\
\hline Antiplatelet & $58(35.4)$ & $410(31.0)$ & 315 (33.4) & $363(31.4)$ & 0.482 \\
\hline Anticoagulation & $9(5.5)$ & $79(6.0)$ & $54(5.7)$ & $64(5.5)$ & 0.969 \\
\hline Statin & 31 (18.9) & $192(14.5)$ & 186 (19.7) & 201 (17.4) & 0.011 \\
\hline
\end{tabular}

NIHSS, National Institute of Health Stroke Scale; SBP, systolic blood pressure. 

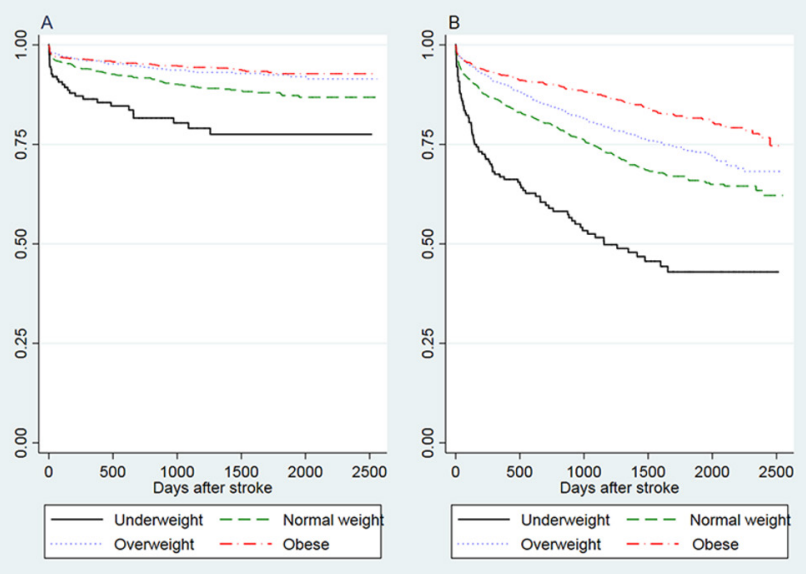

Figure 1 Survival curves for (A) stroke-related mortality and (B) all-cause mortality in patients with ischaemic stroke according to their body mass index. exists only in the elderly patients, whereas it vanishes after covariate adjustment in the younger age group.

A study by Dehlendorff et $a l^{15}$ reported no obesity paradox for stroke-related short-term mortality, which agrees with the findings of this study. Notably, the study mentioned above only considered death incidence within the first month of post-stroke, ${ }^{15}$ whereas we considered later deaths caused by recurrent stroke incidences. The effects of obesity on all-cause mortality in patients with ischaemic stroke revealed that higher BMI slightly increases the survival rate across several conditions, given that all-cause mortality denotes the overall survival across all causes of death. Notably, our results are consistent with previous findings on the obesity paradox in patients with stroke. For instance, a study on stroke survivors in Korea revealed a relatively low 1-year all-cause mortality without any evident paradox for 30-day and 90-day all-cause mortalities. ${ }^{17}$ Findings from this present study also indicate that

Table 3 Adjusted HRs of the obesity status on stroke-related mortalities and cardiovascular-event-related mortality

\begin{tabular}{|c|c|c|c|c|c|c|}
\hline \multirow[b]{2}{*}{ Variables } & \multicolumn{2}{|c|}{3 months } & \multicolumn{2}{|c|}{1 year } & \multicolumn{2}{|c|}{ After 1 year } \\
\hline & SHR & $95 \% \mathrm{Cl}$ & SHR & $95 \% \mathrm{Cl}$ & SHR & $95 \% \mathrm{Cl}$ \\
\hline \multicolumn{7}{|c|}{ Stroke-related mortality } \\
\hline Underweight & 1.63 & 0.91 to 2.91 & 1.52 & 0.93 to 2.48 & 1.39 & 0.91 to 2.12 \\
\hline Normal weight & 1.00 & & 1.00 & & 1.00 & \\
\hline Obese & 1.01 & 0.65 to 1.57 & 0.81 & 0.56 to 1.18 & 0.76 & 0.56 to 1.03 \\
\hline \multicolumn{7}{|l|}{ Model 2† } \\
\hline Underweight & 1.12 & 0.61 to 2.05 & 1.56 & 0.93 to 2.61 & 1.42 & 0.91 to 2.23 \\
\hline Normal weight & 1.00 & & 1.00 & & 1.00 & \\
\hline Overweight & 0.85 & 0.55 to 1.34 & 0.84 & 0.55 to 1.26 & 0.83 & 0.61 to 1.15 \\
\hline
\end{tabular}

Cardiovascular-event-related

mortality

\begin{tabular}{|c|c|c|c|c|c|c|}
\hline \multicolumn{7}{|l|}{ Model $1^{*}$} \\
\hline Underweight & 1.23 & 0.70 to 2.16 & 1.15 & 0.71 to 1.86 & 1.08 & 0.72 to 1.62 \\
\hline Normal weight & 1.00 & & 1.00 & & 1.00 & \\
\hline Obese & 0.83 & 0.55 to 1.25 & 0.70 & 0.49 to 0.99 & 0.67 & 0.51 to 0.89 \\
\hline \multicolumn{7}{|l|}{ Model 2† } \\
\hline Normal weight & 1.00 & & 1.00 & & 1.00 & \\
\hline Overweight & 0.85 & 0.54 to 1.33 & 0.86 & 0.60 to 1.23 & 0.83 & 0.63 to 1.11 \\
\hline Obese & 0.87 & 0.56 to 1.35 & 0.73 & 0.50 to 1.07 & 0.66 & 0.49 to 0.90 \\
\hline
\end{tabular}

*Model 1 was adjusted for age, gender and smoking status.

†Model 2 adjusted the following covariates in addition to what were controlled in Model 1: comorbidities (diabetes, old stroke, atrial fibrillation, active cancer, anaemia, renal disease, liver disease, hypercholesterolaemia, depression, dementia, any complications, initial systolic blood pressure status, total cholesterol, initial glucose level and Charlson comorbidity index), enrolment year, stroke severity measured using the NIHSS score, treatment modalities (any thrombolysis, tissue plasminogen activator, intra-arterial thrombolysis, mechanical thrombectomy and stent insertion) and statin use.

NIHSS, National Institute of Health Stroke Scale; SHR, subdistribution hazard ratio. 
Table 4 All-cause mortality stratified by age group

\begin{tabular}{|c|c|c|c|c|c|c|}
\hline \multirow[b]{2}{*}{ Variables } & \multicolumn{2}{|c|}{3 months } & \multicolumn{2}{|c|}{1 year } & \multicolumn{2}{|c|}{ After 1 year } \\
\hline & HR & $95 \% \mathrm{Cl}$ & HR & $95 \% \mathrm{Cl}$ & HR & $95 \% \mathrm{Cl}$ \\
\hline \multicolumn{7}{|l|}{ Model $1^{*}$} \\
\hline \multicolumn{7}{|l|}{ Total cohort } \\
\hline Underweight & 1.96 & 1.31 to 2.93 & 1.89 & 1.37 to 2.59 & 1.61 & 1.25 to 2.09 \\
\hline Normal weight & 1.00 & & & & & \\
\hline Overweight & 0.60 & 0.42 to 0.85 & 0.70 & 0.54 to 0.90 & 0.83 & 0.70 to 0.98 \\
\hline Obese & 0.67 & 0.48 to 0.94 & 0.63 & 0.48 to 0.82 & 0.63 & 0.53 to 0.82 \\
\hline \multicolumn{7}{|l|}{ Age $<65$ years } \\
\hline Underweight & 3.75 & 1.66 to 8.47 & 3.49 & 1.36 to 7.22 & 2.54 & 1.32 to 4.89 \\
\hline Normal weight & 1.00 & & 1.00 & & 1.00 & \\
\hline Overweight & 0.81 & 0.41 to 1.56 & 0.83 & 0.48 to 1.46 & 0.91 & 0.61 to 1.34 \\
\hline Obese & 0.28 & 0.12 to 0.63 & 0.53 & 0.30 to 0.91 & 0.58 & 0.39 to 0.86 \\
\hline \multicolumn{7}{|l|}{ Age $\geq 65$ years } \\
\hline Underweight & 1.57 & 1.00 to 2.47 & 1.59 & 1.12 to 2.25 & 1.46 & 1.10 to 1.93 \\
\hline Normal weight & 1.00 & & 1.00 & & 1.00 & \\
\hline Overweight & 0.54 & 0.36 to 0.81 & 0.67 & 0.51 to 0.89 & 0.82 & 0.68 to 0.99 \\
\hline Obese & 0.89 & 0.62 to 1.27 & 0.70 & 0.52 to 0.93 & 0.6 & 0.54 to 0.82 \\
\hline \multicolumn{7}{|l|}{ Model $2 \dagger$} \\
\hline \multicolumn{7}{|l|}{ Total cohort } \\
\hline Underweight & 1.55 & $1.00-2.47$ & 1.54 & $1.09-2.18$ & 1.43 & $1.09-1.87$ \\
\hline Normal weight & 1.00 & & 1.00 & & 1.00 & \\
\hline Overweight & 0.78 & $0.54-1.13$ & 0.89 & $0.69-1.14$ & 0.98 & $0.82-1.16$ \\
\hline Obese & 0.81 & $0.56-1.16$ & 0.73 & $0.55-0.99$ & 0.66 & $0.54-0.82$ \\
\hline \multicolumn{7}{|l|}{ Age $<65$ years } \\
\hline Underweight & 0.64 & 0.15 to 2.82 & 0.73 & 0.22 to 2.44 & 0.98 & 0.41 to 2.35 \\
\hline Normal weight & 1.00 & & 1.00 & & 1.00 & \\
\hline Overweight & 1.27 & 0.59 to 2.74 & 1.36 & 0.73 to 2.54 & 1.43 & 0.92 to 2.21 \\
\hline Obese & 0.43 & 0.17 to 1.12 & 0.72 & 0.40 to 1.31 & 0.77 & 0.49 to 1.21 \\
\hline \multicolumn{7}{|l|}{ Age $\geq 65$ years } \\
\hline Underweight & 1.49 & 0.92 to 2.41 & 1.50 & 1.03 to 2.19 & 1.42 & 1.06 to 1.92 \\
\hline Normal weight & 1.00 & & 1.00 & & 1.00 & \\
\hline Overweight & 0.59 & 0.39 to 0.91 & 0.77 & 0.58 to 1.02 & 0.91 & 0.75 to 1.10 \\
\hline Obese & 0.96 & 0.65 to 1.44 & 0.73 & 0.52 to 1.03 & 0.65 & 0.52 to 0.83 \\
\hline
\end{tabular}

*Model 1 was adjusted for age, gender and smoking status.

†Model 2 adjusted the following covariates in addition to what were controlled in Model 1: comorbidities (diabetes, old stroke, atrial fibrillation, active cancer, anaemia, renal disease, liver disease, hypercholesterolaemia, depression, dementia, any complications, initial systolic blood pressure status, total cholesterol, initial glucose level and Charlson comorbidity index), enrolment year, stroke severity measured using the NIHSS score, treatment modalities (any thrombolysis, tissue plasminogen activator, intra-arterial thrombolysis, mechanical thrombectomy and stent insertion) and statin use.

NIHSS, National Institute of Health Stroke Scale.

the underweight group persistently had a higher all-cause mortality risk during short-term, intermediate-term and long-term follow-up periods, and the mortality risk of the overweight group is similar to that of the normal weight group at all points. Furthermore, our study was corroborated by previous findings on increased mortality risk among underweight stroke survivors. Underweight is consistently associated with increased mortality after stroke, ${ }^{3561517184243}$ although the impact of obesity on mortality was reported in a conflicting direction.

After controlling the confounding factors, we observed that the obesity paradox for the all-cause mortality is only found in patients aged 65 years and above. It has been shown that adults aged 65 years and above experience 


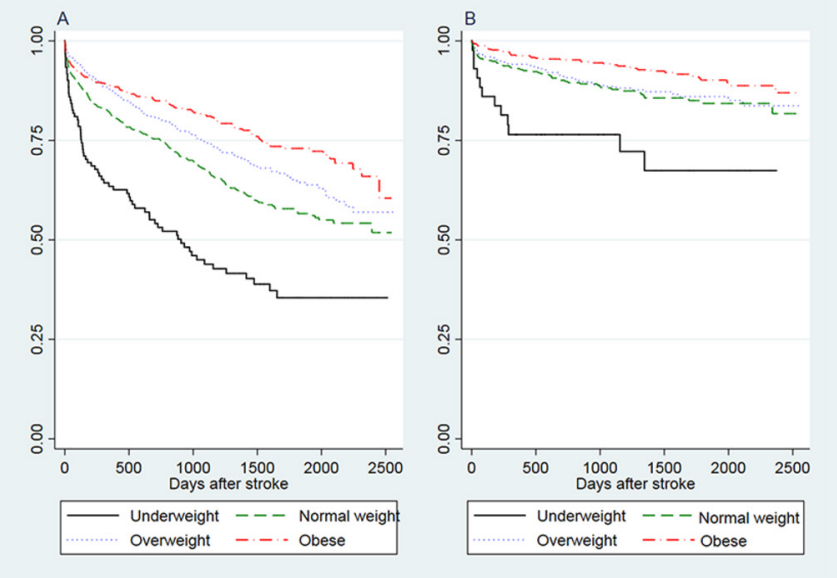

Figure 2 Survival curves in (A) elderly and (B) younger patients with ischaemic stroke according to their body mass index.

weight loss more frequently than weight gain. ${ }^{44}$ In addition, weight loss has been shown to be associated with higher mortality risk in older adults ${ }^{445}$ and even predict mortality independent from chronic disease. ${ }^{46} 47$ Another possible explanation for such obesity paradox is a subset of obese people classified as metabolically healthy obese. ${ }^{48}$ These people seem to be more resistant to the development of obesity-related metabolic diseases. In a study with elderly Koreans aged 60 years and above, the metabolically non-healthy normal weight people were observed to have a remarkably higher risk of all-cause and cardiovascular disease mortality than the overweight or obese people without metabolic syndrome. ${ }^{48}$

As far as we know, only a few studies have compared the obesity paradox based on age group ${ }^{41743}$; even so, the findings were inconsistent. The findings of some of those studies agreed with the results obtained in this study and reported the obesity paradox in patients aged 65 years and above. ${ }^{42}$ Towfighi et al ${ }^{4}$ reported that obesity is associated with reduced mortality only among elderly survivors. ${ }^{4}$ A study with women aged $50-79$ years also showed that being overweight or obese is associated with low poststroke mortality. ${ }^{42}$ Meanwhile, in contrast with our results, some studies reported that the obesity paradox is more prominent in younger patients ${ }^{17} 43$ and more prominent in patients with stroke aged less than 65 years. However, it is worth noting that in our study, the obesity paradox in the younger age group became statistically insignificant after adjustment of detailed comorbidities, despite being significant and even more noticeable in the younger age group before the adjustment. This shows that the conflicting results on the obesity paradox in the younger age group might be due to the different methods used in controlling the critical confounding variables in different studies. Considering the relatively small number of participants and deaths in the younger subgroup, larger-scale studies with better control of confounders are needed to enhance further the understanding of the obesity paradox based on age groups. Nevertheless, our findings in this study suggest that, at least in elderly patients with stroke, obesity is not necessarily a risk for mortality.

The obesity paradox in chronic diseases could be explained through biological mechanisms focusing on the advantage of excess fat during illness. ${ }^{49}$ For instance, weight loss after stroke is a commonly observed phenomenon, which is explained by various mechanisms such as sympathetic activation, fever and inflammation. ${ }^{50}$ Individuals may lose homeostatic capacity and become more susceptible to the catabolic effect of chronic morbidity or complications. Owing to better metabolic reserves in obese patients, unfavourable metabolic dysregulation might be less common in obese patients. ${ }^{50}$

Despite the biological explanation, some studies also raised concerns about inadequate control of confounding variables and reverse causation of the underlying reasons for the observed obesity paradox. Reverse causation occurs when low BMI is not an independent risk factor; instead, it is a consequence of underlying conditions that cause weight loss and then lead to death. However, several studies reported that the mortality risk does not change after excluding patients with life-threatening diseases such as cancer or those who died early in the follow-up period. ${ }^{5152}$ Several studies, including this present study, showed that confounders such as smoking and comorbidities could not entirely explain the obesity paradox. ${ }^{23561742}$ A related empirical concern regarding the obesity paradox is a collider-stratification bias that results from conditioning the common effects of exposure and outcome. ${ }^{49}$ For example, atrial fibrillation, a common risk factor for both ischaemic stroke and mortality, ${ }^{1}$ is a higher risk for mortality than obesity among patients with stroke; thus, one could falsely observe the protective effect of obesity on mortality when not adjusting for atrial fibrillation in obesity regression on stroke-related mortality. This highlights the importance of comprehensive control of comorbidities and stroke severity in estimating the obesity paradox in patients with stroke as in the current study. We acknowledge that there are conflicting findings in previous studies regarding the collider bias and obesity paradox after controlling for it. ${ }^{15} 53$ This study adjusted for stroke severity and various comorbidities using CCI to estimate the net effect of obesity on mortality in patients with stroke considering the effect that may result because of the uncertainty of the kind of relationship that exists between various comorbidities with obesity and mortality.

Notwithstanding, this study has several limitations. First, this is a hospital-based study involving a single tertiary hospital whose data could not be generalised. However, this could also be an advantage of the study. Since patients received relatively uniform treatments at the same hospital, a potential confounder from different treatments could be minimised. Moreover, we retrieved the data from a registry in which the clinical information had been maintained in a standard pre-defined way. Second, we evaluated the body composition 
as BMI, which cannot differentiate between elevated body fat content and preserved or increased lean mass. ${ }^{54}$ Measurement of fat distribution such as waist-to-hip ratio or waist circumference could probably be more suitable in assessing the effect of obesity on stroke-related mortality. Third, in the analysis, we excluded patients without BMI information. The missing weight or height data could be due to the patient's extremely severe status or inability to stand up. These patients without recorded body weight and height information apparently had a higher NIHSS score and higher mortality rate in the unadjusted analysis. Therefore, in this study, it is possible that the obesity paradox was underestimated by excluding the patients with missing BMI data.

Despite the shortcomings, this study made several significant contributions. First, we evaluated the relationship between BMI and mortality risk by controlling the variables related to various diseases, which could not be obtained in previous studies, including some potential confounders such as active cancer, depression, dementia, anaemia, other medical severity at admission and complications during stroke treatment. Second, as mentioned earlier, we addressed the existence of multi-morbidity by CCI. To the best of our knowledge, CCI has not been considered a confounding variable in any study in analysing the effect of the obesity paradox on mortality in stroke survivors. ${ }^{2-6151718424355}$ Third, the covariates measurements were rigorously performed. Previous studies included initial blood pressure or glucose level as a surrogate marker of cardiovascular disease severity. However, they did not mention the risk associated with the assessment method but only considered the increment in those levels as a severity indicator. $^{2} 1755$

\section{Author affiliations}

${ }^{1}$ Department of Pharmaceutical Medicine and Regulatory Sciences, College of Medicine and Pharmacy, Yonsei Institute of Pharmaceutical Sciences, Yonsei University, Seoul, South Korea

${ }^{2}$ Department of Internal Medicine, Korea University Ansan Hospital, Ansan, Republic of Korea

${ }^{3}$ Department of Neurology, Yonsei University College of Medicine, Seoul, Republic of Korea

${ }^{4}$ Department of Pharmacy, Yonsei Institute of Pharmaceutical Sciences, College of Pharmacy, Yonsei University, Seoul, Republic of Korea

Contributors EH and HSN had full access to all of the data in the study and take responsibility for the integrity of the data and the accuracy of the data analysis. EH is behind the conception of the research and study design, whereas $\mathrm{HC}$ drafted the manuscript. A critical review of the manuscript was carried out by EH, HSN and HC. All authors have read and approved the final version of the manuscript.

Funding Research support from the Korea National Research Foundation (NRF 2019R1A2C1003259) is gratefully acknowledged. The content is solely the responsibility of the authors and does not necessarily represent the official view of the Korea National Research Foundation. The Korea National Research Foundation had no involvement in preparation and submission of this manuscript.

Competing interests None declared.

Patient consent for publication Not required.
Ethics approval This study was approved by the Severance Hospital Institutional Review Board, Yonsei University Health System (4-2015-1196). Informed consent was obtained from the patients, and the data were anonymous.

Provenance and peer review Not commissioned; externally peer reviewed.

Data availability statement Data may be obtained from a third party and are not publicly available.

Open access This is an open access article distributed in accordance with the Creative Commons Attribution Non Commercial (CC BY-NC 4.0) license, which permits others to distribute, remix, adapt, build upon this work non-commercially, and license their derivative works on different terms, provided the original work is properly cited, appropriate credit is given, any changes made indicated, and the use is non-commercial. See: http://creativecommons.org/licenses/by-nc/4.0/.

\section{REFERENCES}

1. Kernan WN, Ovbiagele B, Black HR, et al. Guidelines for the prevention of stroke in patients with stroke and transient ischemic attack: a guideline for healthcare professionals from the American heart Association/American stroke association. Stroke 2014;45:2160-236.

2. Vemmos K, Ntaios G, Spengos K, et al. Association between obesity and mortality after acute first-ever stroke: the obesity-stroke paradox. Stroke 2011;42:30-6.

3. Olsen TS, Dehlendorff C, Petersen HG, et al. Body mass index and poststroke mortality. Neuroepidemiology 2008;30:93-100.

4. Towfighi A, Ovbiagele B. The impact of body mass index on mortality after stroke. Stroke 2009;40:2704-8.

5. Doehner W, Schenkel J, Anker SD, et al. Overweight and obesity are associated with improved survival, functional outcome, and stroke recurrence after acute stroke or transient ischaemic attack: observations from the TEMPiS trial. Eur Heart J 2013;34:268-77.

6. Andersen KK, Olsen TS. The obesity paradox in stroke: lower mortality and lower risk of readmission for recurrent stroke in obese stroke patients. Int J Stroke 2015;10:99-104.

7. Barba R, Marco J, Ruiz J, et al. The obesity paradox in stroke: impact on mortality and short-term readmission. J Stroke Cerebrovasc Dis 2015;24:766-70.

8. Andersen KK, Olsen TS. Body mass index and stroke: overweight and obesity less often associated with stroke recurrence. J Stroke Cerebrovasc Dis 2013;22:e576-81.

9. Anker SD, von Haehling $\mathrm{S}$. The obesity paradox in heart failure: accepting reality and making rational decisions. Clin Pharmacol Ther 2011;90:188-90.

10. Kato J. Obesity paradox in peripheral vascular disease. Atherosclerosis 2013;229:509-10.

11. Florez H, Castillo-Florez S. Beyond the obesity paradox in diabetes: fitness, fatness, and mortality. JAMA 2012;308:619-20.

12. Schmidt $D$, Salahudeen $A$. The obesity-survival paradox in hemodialysis patients: why do overweight hemodialysis patients live longer? Nutr Clin Pract 2007;22:11-15.

13. Ferreira I, Stehouwer CDA. Obesity paradox or inappropriate study designs? time for life-course epidemiology. J Hypertens 2012;30:2271-5.

14. Banack HR, Kaufman JS. The "Obesity Paradox" Explained. Epidemiology 2013;24:461-2.

15. Dehlendorff C, Andersen KK, Olsen TS. Body mass index and death by stroke: no obesity paradox. JAMA Neurol 2014;71:978-84.

16. Hastie CE, Padmanabhan S, Slack R, et al. Obesity paradox in a cohort of 4880 consecutive patients undergoing percutaneous coronary intervention. Eur Heart J 2010;31:222-6.

17. Kim BJ, Lee S-H, Jung K-H, et al. Dynamics of obesity paradox after stroke, related to time from onset, age, and causes of death. Neurology 2012;79:856-63.

18. Ryu W-S, Lee S-H, Kim CK, et al. Body mass index, initial neurological severity and long-term mortality in ischemic stroke. Cerebrovasc Dis 2011;32:170-6.

19. Kim Y, Kim CK, Jung S, et al. Obesity-stroke paradox and initial neurological severity. J Neurol Neurosurg Psychiatry 2015;86:743-7.

20. Lee BI, Nam HS, Heo JH, et al. Yonsei stroke Registry. Analysis of 1,000 patients with acute cerebral infarctions. Cerebrovasc Dis 2001;12:145-51.

21. Nam HS, Kim HC, Kim YD, et al. Long-Term mortality in patients with stroke of undetermined etiology. Stroke 2012;43:2948-56.

22. World Health Organization. The Asia-Pacific perspective: redefining obesity and its treatment. Sydney: Health Communications Australia, 2000. 
23. Brott T, Marler JR, Olinger CP, et al. Measurements of acute cerebral infarction: lesion size by computed tomography. Stroke 1989;20:871-5

24. Grysiewicz RA, Thomas K, Pandey DK. Epidemiology of ischemic and hemorrhagic stroke: incidence, prevalence, mortality, and risk factors. Neurol Clin 2008;26:871-95.

25. Persky RW, Turtzo LC, McCullough LD. Stroke in women: disparities and outcomes. Curr Cardiol Rep 2010;12:6-13.

26. Bushnell C, McCullough LD, Awad IA, et al. Guidelines for the prevention of stroke in women: a statement for healthcare professionals from the American heart Association/American stroke association. Stroke 2014;45:1545-88.

27. Kawachi let al. Smoking cessation and decreased risk of stroke in women. JAMA 1993;269:232-6.

28. Wannamethee SGet al. Smoking cessation and the risk of stroke in middle-aged men. JAMA 1995;274:155-60.

29. Heuschmann PUet al. Predictors of In-Hospital Mortality and Attributable Risks of Death After Ischemic Stroke<subtitle $>$ The German Stroke Registers Study Group</subtitle\&gt. Arch Intern Med 2004;164:1761-8.

30. The Emerging Risk Factors Collaboration . Diabetes mellitus, fasting blood glucose concentration, and risk of vascular disease: a collaborative meta-analysis of 102 prospective studies. The Lancet 2010;375:2215-22.

31. Zhang $\mathrm{X}$, Patel $\mathrm{A}$, Horibe $\mathrm{H}$, et al. Cholesterol, coronary heart disease, and stroke in the Asia Pacific region. Int $J$ Epidemiol 2003;32:563-72.

32. Pan A, Sun Q, Okereke Ol, et al. Depression and risk of stroke morbidity and mortality: a meta-analysis and systematic review. Jama 2011;306:1241-9.

33. Tatemichi TK, Paik M, Bagiella E, et al. Dementia after stroke is a predictor of long-term survival. Stroke 1994;25:1915-9.

34. Lawler PR, Filion KB, Dourian T, et al. Anemia and mortality in acute coronary syndromes: a systematic review and meta-analysis. Am Heart J 2013;165:143-53

35. Kaarisalo MM, Immonen-Räihä P, Marttila RJ, et al. Atrial fibrillation and stroke: mortality and causes of death after the first acute ischemic stroke. Stroke 1997;28:311-5.

36. den Exter PL, Hooijer J, Dekkers OM, et al. Risk of recurrent venous thromboembolism and mortality in patients with cancer incidentally diagnosed with pulmonary embolism: a comparison with symptomatic patients. JCO 2011;29:2405-9.

37. D'Hoore W, Sicotte C, Tilquin C. Risk adjustment in outcome assessment: the Charlson comorbidity index. Methods Inf Med 1993;32:382-7.

38. Whelton PK, Carey RM, Aronow WS, et al. ACC/AHA/AAPA ABC/ACPM/AGS/APhA/ASH/ASPC/NMA/PCNA guideline for the prevention, detection, evaluation, and management of high blood pressure in adults: a report of the American College of Cardiology/ American heart association Task force on clinical practice guidelines. J Am Coll Cardiol 2017;2018:e127-248.
39. Seaquist ER, Anderson J, Childs B, et al. Hypoglycemia and diabetes: a report of a Workgroup of the American diabetes association and the endocrine Society. J Clin Endocrinol Metab 2013;98:1845-59.

40. Powers WJ, Rabinstein AA, Ackerson T, et al. Guidelines for the early management of patients with acute ischemic stroke: a guideline for healthcare professionals from the American heart Association/American stroke association. Stroke 2018;2018:e46-99.

41. Olsen TS, Langhorne P, Diener HC, et al. European stroke initiative recommendations for stroke Management-update 2003. Cerebrovasc Dis 2003;16:311-37.

42. Bell CL, LaCroix A, Masaki K, et al. Prestroke factors associated with poststroke mortality and recovery in older women in the women's health Initiative. J Am Geriatr Soc 2013;61:1324-30.

43. Skolarus LE, Sanchez BN, Levine DA, et al. Association of body mass index and mortality after acute ischemic stroke. Circulation 2014;7:64-9.

44. Newman AB, Yanez D, Harris T, et al. Weight change in old age and its association with mortality. J Am Geriatr Soc 2001;49:1309-18.

45. Wannamethee SG, Shaper AG, Whincup PH, et al. Characteristics of older men who lose weight intentionally or unintentionally. $A m \mathrm{~J}$ Epidemiol 2000;151:667-75.

46. Alley DE, Metter EJ, Griswold ME, et al. Changes in weight at the end of life: characterizing weight loss by time to death in a cohort study of older men. Am J Epidemiol 2010;172:558-65.

47. Nilsson PM, Nilsson JA, Hedblad B, et al. The enigma of increased non-cancer mortality after weight loss in healthy men who are overweight or obese. J Intern Med 2002;252:70-8.

48. Choi KM, Cho HJ, Choi HY, et al. Higher mortality in metabolically obese normal-weight people than in metabolically healthy obese subjects in elderly Koreans. Clin Endocrinol 2013;79:364-70.

49. Banack HR, Kaufman JS. The obesity paradox: understanding the effect of obesity on mortality among individuals with cardiovascular disease. Prev Med 2014;62:96-102.

50. Scherbakov N, Dirnagl U, Doehner W. Body weight after stroke: lessons from the obesity paradox. Stroke 2011;42:3646-50.

51. Allison DB, Faith MS, Heo M, et al. Meta-Analysis of the effect of excluding early deaths on the estimated relationship between body mass index and mortality. Obes Res 1999;7:342-54.

52. Stevens Jet al. Fitness and fatness as predictors of mortality from all causes and from cardiovascular disease in men and women in the lipid research clinics study. Am J Epidemiol 2002;156:832-41.

53. Sperrin M, Candlish J, Badrick E, et al. Collider bias is only a partial explanation for the obesity paradox. Epidemiology 2016;27:525-30.

54. Frankenfield DC, Rowe WA, Cooney RN, et al. Limits of body mass index to detect obesity and predict body composition. Nutrition $2001 ; 17: 26-30$.

55. Kim BJ, Lee S-H, Ryu W-S, et al. Paradoxical longevity in obese patients with intracerebral hemorrhage. Neurology 2011;76:567-73. 